\title{
Wavelet analysis of the singular spectral reconstructed time series to study the imprints of solar-ENSO-geomagnetic activity on Indian climate
}

\author{
Sri Lakshmi Sunkara ${ }^{1}$ and Rama Krishna Tiwari ${ }^{2}$ \\ ${ }^{1}$ University Centre for Earth and Space Sciences, University of Hyderabad, 500046 Hyderabad, India \\ ${ }^{2}$ CSIR-National Geophysical Research Institute, Uppal Road, 500007 Hyderabad, India
}

Correspondence to: Sri Lakshmi Sunkara (srilakshmi.ucess@gmail.com)

Received: 24 February 2015 - Published in Nonlin. Processes Geophys. Discuss.: 28 September 2015

Revised: 9 August 2016 - Accepted: 22 August 2016 - Published: 20 September 2016

\begin{abstract}
To study the imprints of the solar-ENSOgeomagnetic activity on the Indian subcontinent, we have applied singular spectral analysis (SSA) and wavelet analysis to the tree-ring temperature variability record from the Western Himalayas. Other data used in the present study are the solar sunspot number (SSN), geomagnetic indices (aa index), and the Southern Oscillation Index (SOI) for the common time period of 1876-2000. Both SSA and wavelet spectral analyses reveal the presence of 5-7-year short-term ENSO variations and the 11-year solar cycle, indicating the possible combined influences of solar-geomagnetic activities and ENSO on the Indian temperature. Another prominent signal corresponding to 33-year periodicity in the tree-ring record suggests the Sun-temperature variability link probably induced by changes in the basic state of the Earth's atmosphere. In order to complement the above findings, we performed a wavelet analysis of SSA reconstructed time series, which agrees well with our earlier results and increases the signalto-noise ratio, thereby showing the strong influence of solargeomagnetic activity and ENSO throughout the entire period. The solar flares are considered responsible for causing the atmospheric circulation patterns. The net effect of solargeomagnetic processes on the temperature record might suggest counteracting influences on shorter (about 5-6-year) and longer (about 11-12-year) timescales. The present analyses suggest that the influence of solar activities on the Indian temperature variability operates in part indirectly through coupling of ENSO on multilateral timescales. The analyses, hence, provide credible evidence of teleconnections of tropical Pacific climatic variability and Indian climate rang-
\end{abstract}

ing from inter-annual to decadal timescales and also suggest the possible role of exogenic triggering in reorganizing the global Earth-ocean-atmospheric systems.

\section{Introduction}

Several recent studies of solar-geomagnetic effects on climate have been examined on both global as well as on regional scales (Lean and Rind, 2008; Benestaed and Schmidt, 2009; Meehl et al., 2009; Kiladis and Diaz, 1989; Pant and Rupa Kumar, 1997; Gray et al., 1992; Wiles et al., 1998; Friis and Svensmark, 1997; Rigozo et al., 2005; Feng et al., 2003; Tiwari and Srilakshmi, 2009; Chowdary et al., 2006, 2014; Appenzeller et al., 1998; Proctor et al., 2002; Tsonis et al., 2005; De Freitas and Mclean, 2013). The Sun's long-term magnetic variability caused by the sunspots is considered to be one of the primary drivers of climatic changes. The shortterm magnetic variability is due to the disturbances in the Earth's magnetic fields caused by the solar activities and is indicated by the geomagnetic indices. The Sun's magnetic variability modulates the magnetic and particulate fluxes in the heliosphere. This determines the interplanetary conditions and imposes significant electromagnetic forces and effects upon the planetary atmosphere. All these effects are due to the changing solar-magnetic fields, which are relevant for planetary climates, including the climate of the Earth. The Sun-Earth relationship varies on different timescales ranging from days to years, bringing a drastic influence on the climatic patterns. The ultimate cause of solar variability, on 
timescales from decadal to centennial to millennial or even longer scales, has its origin in the solar dynamo mechanism. During the solar maxima, huge amounts of solar energy particles are released, thereby causing the geomagnetic disturbances. The 11-year solar cycle acts as an important driving force for variations in the space weather, ultimately giving rise to climatic changes. It is, therefore, imperative to understand the origin of space climate by analyzing the different proxies of solar-magnetic variabilities. Another important phenomenon is El Niño-Southern Oscillation (ENSO), which is associated with droughts, floods, and intense rainfall in different parts of the world. The strong coupling and interactions between the tropical ocean and the atmosphere play a major role in the development of the global climatic system. The El Niño events generally recur approximately every 3-5 years, with large events spaced around 3-7 years apart. The ENSO phenomena have shown a huge impact on the Asian monsoon (Cole et al., 1993), Indian monsoon (Chowdary et al., 2006, 2014), as well as globally (Horel and Wallance, 1981; Barnett, 1989; Yasunari, 1985; Nicolson, 1997). In particular, the El Niño, solar, geomagnetic activities are the major affecting forces on the decadal and interdecadal temperature variability on global and regional scales in a direct/indirect way (El-Borie et al., 2010; Gray et al., 2010). Recent studies (Frohlich and Lean, 2004; Steinhilber et al., 2009) indicate the possible influence of solar activity on Earth's temperature/climate on multi-decadal timescales. The 11-year solar cyclic variations observed from the several temperature climate records also suggest the impact of solar irradiance variability on terrestrial temperature (Budyko, 1969; Friis and Lassen, 1991; Friis and Svensmark, 1997; Kasatkina et al., 2007). The bi-decadal (22-year) cycle, called the Hale cycle, is related to the reversal of the solar-magnetic field direction (Lean et al., 1995; Kasatkina et al., 2007). The 33-year cycle (Bruckener cycle) is also caused by the solar origin, but it is a very rare cycle (Kasatkina et al., 2007). The 2-7-year ENSO cyclic pattern and its possible coupling process are the major driving forces for the temperature variability (Gray et al., 1992; Wiles et al., 1998; Mokhov et al., 2000; Rigozo et al., 2007, Kothawale et al., 2010). El-Borie and Al-Thoyaib (2006) and El-Borie et al. $(2007,2010)$ have indicated in their studies that the global temperature should lag the geomagnetic activity with a maximum correlation when the temperature lags by 6 years. Mendoza et al. (1991) reported on possible connections between solar activity and El Niños, while Reid and Gage (1988) and Reid (1991) reported on the similarities between the 11-year running means of monthly sunspot numbers and global sea surface temperature. These findings suggest that there is a possibility of strong coupling between temperature-ENSO and solar-geomagnetic signals.

Several studies have been carried out to understand the climatic changes of India in the past millennium using various proxy records, e.g., ice cores, lake sediments, glacier fluctuations, and peat deposits. There is a lack of high-precision and high-resolution palaeo-climatic information for longer timescales from the Indian subcontinent. Tree-ring data are a promising proxy to retrieve high-resolution past climatic changes from several geographical regions of India (Bhattacharyya et al., 1988, 1992, 2006; Hughes, 1992; Bhattacharyya and Yadav, 1996; Borgaonkar et al., 1996; Chaudhary et al., 1999; Yadav et al., 1999; Bhattacharyya and Chaudhary, 2003; Shah et al., 2007). It has been noted that tree-ring-based climatic reconstructions in India generally do not exceed 400-year records except at some sites in the northwestern Himalaya. Thus, a long record of tree-ring data is needed to extend available climate reconstruction further back to determine climatic variability on sub-decadal, decadal, and century scales. However, non-availability of older living trees at most of the sites is hindering the preparation of a long tree chronology. In a previous study (Tiwari and Srilakshmi, 2009), we have studied the periodicities and non-stationary modes in the tree-ring temperature data from the same region (AD 1200-2000). To reveal significant connections among the solar-geomagnetic-ENSO "triad" phenomena on tree-ring width in detail for the period from 1876 to 2000, we have applied here singular spectral analysis (SSA) and the wavelet spectral analysis for sunspot data, geomagnetic data (aa index), the Troup Southern Oscillation Index (SOI), and the Western Himalayan treering data. Here our main objective is to employ waveletbased analysis in SSA reconstructed time series to find evidence of the possible linkages, if any, among ENSO-solargeomagnetic activity in the Indian temperature records.

\section{Source and nature of data}

The data analyzed here include the time series of the (1) smoothed sunspot number for solar activity, (2) geomagnetic activity data (aa indices), (3) the Troup Southern Oscillation Index (SOI) for the study of the El NiñoSouthern Oscillation, called ENSO, and (4) the Western Himalayan temperature variability record. All the data sets have been analyzed for the common period of 125 years spanning over 1876-2000. The monthly sunspot number data have been obtained from the Sunspot Index Data Center (http://astro.oma.be/SIDC/). The Troup SOI data are obtained from the Bureau of Meteorology of Australia (http: //www.bom.gov.au/climate/). The data for geomagnetic activity, the aa index, were provided by the National Geophysical Data Center, NGDC (http://www.ngdc.noaa.gov/ stp/GEOMAG/aastar.shtml). The aa index is a measure of the disturbance level of Earth's magnetic field based on magnetometer observations at two, nearly antipodal, stations in Australia and England. In recent studies, the tree-ring proxy climate indicators are being used for extracting information regarding past seasonal temperature or precipitation/drought based on the measurements of annual ring width. The detailed description of the data has been pre- 
sented elsewhere (Yadav et al., 2004). A brief account of the data pertinent to the present analysis, however, is summarized here. The tree-ring data being analyzed here are one of the best temperature variability records (1876-2000) of the pre-monsoon season in the Western Himalayas available. The mean temperature series is obtained from nine weather stations including both from high- and low-elevation areas in the Western Himalayas. Temperature variability history is based on widely spread pure Himalayan cedar (Cedrus deodara (Roxb.) G. Don) trees and characterizes all the sites with almost no ground vegetation, thereby minimizing individual variation in tree-ring sequences induced by inter-tree competition (Yadav et al., 2004). The mean chronological structure is based on a total of 60 radii from 45 trees in total, the statistical feature of which shows that the chronology is suitable for dendro-climatic studies back to AD 1226 (Yadav et al., 2004).

\section{Methods applied}

To analyze the temporal series and to find the climatic structure, we have here three methods: principal component analysis (PCA), singular spectral analysis (SSA), and wavelet analysis.

\subsection{Principal component analysis (PCA)}

As a preliminary analysis, we have applied principal component analysis (PCA) to the data sets for the reduction and extraction of dimensionality of the data and to rate the amount of variation present in the original data set. The purpose of applying PCA is to identify patterns in the given time series. The new components thereby obtained by the PCA analysis are termed PC1, PC2, PC3, and so on (for the first, second, and third principal components), and are uncorrelated. The different PCs capture part of the variance and are ranked depending on their corresponding percentage variance.

\subsection{Singular spectral analysis}

The singular spectrum analysis (SSA) method is designed to extract as much information as possible from a short, noisy time series without any prior knowledge about the dynamics underlying the series (Broomhead and King, 1986; Vautard and Ghil, 1989; Alonso et al., 2005; Golyandina et al., 2001). The method is a form of principal component analysis (PCA) applied to lag-correlation structures of the time series. The basic SSA decomposes an original time series into a new series that consists of trend, periodic or quasiperiodic, and white noises according to singular value decomposition (SVD), and provides the reconstructed components (RCs). The basic steps involved in SSA are decomposition (involves embedding and singular value decomposition, SVD) and reconstruction (involves grouping and diagonal averaging). Embedding decomposes the original time series into the trajectory matrix; SVD turns the trajectory matrix into the decomposed trajectory matrices. The reconstruction stage involves grouping to make subgroups of the decomposed trajectory matrices and diagonal averaging to reconstruct the new time series from the subgroups.

\subsubsection{Step 1: decomposition}

a. Embedding: the first step in the basic SSA algorithm is the embedding step where the initial time series change into the trajectory matrix. Let the time series be $Y=\left\{y_{1}, \ldots, y_{N}\right\}$ of length $N$ without any missing values. Here the window length $L$ is chosen such that $2<L<N / 2$ to embed the initial time series. We map the time series $Y$ into the $L$ lagged vectors, $Y_{i}=\left\{y_{i}\right.$, $\ldots, y_{i+L-1}$ for $i=1 \ldots K$, where $K=N-L+1$. The trajectory matrix $\mathbf{T}_{Y}(L \times K$ dimensions $)$ is written as

$$
\mathbf{T}_{Y}=\left(\begin{array}{c}
Y_{1} \\
Y_{2} \\
\cdot \\
\cdot \\
Y_{K}
\end{array}\right) \text {. }
$$

b. Singular value decomposition (SVD): here we apply SVD to the trajectory matrix $\mathbf{T}_{Y}$ to decompose and obtain $\mathbf{T}_{Y}=U D V^{\prime}$ called eigen triples, where $\mathbf{U}_{i}(K \times L$ dimensions; $1<i<L)$ is an orthonormal matrix; $\mathbf{D}_{i}$ $(1<i<L)$ is a diagonal matrix of order $L$; and $\mathbf{V}_{i}$ ( $L \times L$ dimensions; $1<i<L$ ) is a square orthonormal matrix.

The trajectory matrix is thus written as

$$
\mathbf{T}_{Y}=\sum_{i=1}^{d} \mathbf{U}_{i} \sqrt{\lambda_{i}} \mathbf{V}_{i}^{T},
$$

with the $i$ th eigen triple of $\mathbf{T}_{i}=\mathbf{U}_{i} \times \sqrt{\lambda_{i}} \times \mathbf{V}_{i}^{T}, I=1$, $2,3 \ldots, d$, in which $d=\max \left(i: \sqrt{\lambda_{i}}>0\right)$.

\subsubsection{Step 2: reconstruction}

c. Grouping: here the matrix $\mathbf{T}_{i}$ is decomposed into subgroups according to the trend, periodic or quasi-periodic components, and white noises. The grouping step of the reconstruction stage corresponds to the splitting of the elementary matrices $\mathbf{T}_{i}$ into several groups and summing the matrices within each group. Let $I=\left\{i_{1}, i_{2}\right.$, $\left.\ldots, i_{p}\right\}$ be the group of indices $i_{1}, \ldots i_{p}$. Then the matrix $\mathbf{T}_{I}$ corresponding to the group $I$ is defined as $T_{\mathrm{I}}=\mathbf{T}_{I 1}+\mathbf{T}_{I 2}+\ldots \mathbf{T}_{i p}$. The split of the set of indices $J=1,2, \ldots, d$ into the disjoint subsets $I_{1}, I_{2}, \ldots I_{m}$ corresponds to Eq. (3):

$\mathbf{T}=\mathbf{T}_{I 1}+\mathbf{T}_{I 2}+\ldots \mathbf{T}_{I m}$.

The sets $I_{1}, \ldots, I_{m}$ are called the eigen triple grouping. 
d. Diagonal averaging: the diagonal averaging transfers each matrix $\mathbf{T}$ into a time series, which is an additive component of the initial time series $Y$. If $z_{i j}$ stands for a element matrix $\mathbf{Z}$, the $k$ th term of the resulting series is obtained by averaging $z_{i j}$ over all $i, j$ such that $i+j=k+2$. This is called diagonal averaging or the Hankelization of the matrix $\mathbf{Z}$. The Hankel matrix $\mathbf{H Z}$ is the trajectory matrix corresponding to the series obtained by the result of diagonal averaging.

Considering Eq. (3), let $\mathbf{X}(L \times K)$ be a matrix with elements $x_{i j}$, where $1 \leq i \leq L, 1 \leq j \leq K$. Here diagonal averaging transforms matrix $\mathbf{X}$ into a series $g_{0}, \ldots$, $g_{T-1}$ using the formula

$$
g_{k}= \begin{cases}\frac{1}{k+1} \sum_{m=1}^{k+1} x_{m, k-m+2^{*}} & 0 \leq k<L^{*}-1 \\ \frac{1}{L^{*}} \sum_{m=1}^{L^{*}} x_{m, k-m+2}^{*} & L^{*}-1 \leq k<K^{*} \\ \frac{1}{T-k} \sum_{m=k-k^{*}+2}^{N-k+1} x_{m, k-m+2}^{*} & K^{*}-1 \leq k<T\end{cases}
$$

This diagonal averaging by Eq. (4) applied to the resultant matrix $\mathbf{X}_{I n}$, produces time series $Y_{n}$ of length $T$. For such signal characteristics, it is essential to examine the time-frequency pattern so as to understand whether a particular frequency is temporally consistent or inconsistent. Hence, for non-stationary signals, we need a transform that will be useful to obtain the frequency content of the time series/signal as a function of time.

An alternative method for studying the non-stationarity of the time series is wavelet transform. For nonstationary signals, wavelet decomposition would be the most appropriate method because the analyzing functions (the wavelet functions) are localized both in time and frequency.

\subsection{Wavelet spectral analysis}

During the past decades, wavelet analysis has become a popular method for the analysis of aperiodic and quasi-periodic data (Grinsted et al., 2004; Jevrejeva et al., 2003; Torrence and Compo, 1998; Torrence and Webster, 1999). In particular, it has become an important tool for studying localized variations of power within a time series. By decomposing a time series into time-frequency space, the dominant modes of variability and their variation with respect to time can be identified. The wavelet transform has various applications in geophysics, including tropical convection (Weng and Lau, 1994) and the El Niño-Southern Oscillation (Gu and Philander, 1995). We have applied the wavelet analysis to analyze the non-stationary signals, which permits the identification of the main periodicities of ENSO-sunspot-geomagnetic activity in the time series. The results give us more insight information about the evolution of these variables in frequencytime mode.
A wavelet transform requires the choice of analyzing function $\Psi$ (called "mother wavelet") that has the specific property of time-frequency localization. The continuous wavelet transform revolves around decomposing the time series into scaling components for identifying oscillations occurring on a fast (time)scale and others on slow scales. Mathematically, the continuous wavelet transform of a time series $f(t)$ can be given as

$W_{\psi}(f)(a, b)=\frac{1}{\sqrt{a}} \int_{-\infty}^{\infty} f(t) \psi\left(\frac{t-b}{a}\right) \mathrm{d} t$.

Here $f(t)$ represents time series and $\Psi$ is the base wavelet function (here we have chosen the Morlet function), with a length that is much shorter than the time series $f(t)$. $W$ stands for wavelet coefficients. The variable " $a$ " is called the scaling parameter that determines the frequency (or scale) so that varying " $a$ " gives rise to the wavelet spectrum. The factor " $b$ " is related to the shift of the analysis window in time so that varying $b$ represents the sliding method of the wavelet over $f(t)$.

In several recent analyses, a complex Morlet wavelet has been found useful for geophysical time series analysis. The Morlet is mostly used to find areas where there is high amplitude at certain frequencies. The complex Morlet wavelet can be represented by a periodic sinusoidal function with a Gaussian envelope and is excellent for a Morlet wavelet that may be defined mathematically, as follows:

$\psi(t)=\pi^{-1 / 4} e^{-i \omega_{0} t} e^{-t^{2} / 2}$,

where $\omega_{0}$ is a non-dimensional value. $\omega_{0}$ is chosen to be 5 to make the highest and lowest values of $\psi$ approximately equal to 0.5 , thus satisfying the admissibility condition. The complex-valued Morlet transform enables us to extract information about the amplitude and phase of the signal to be analyzed. Wavelet transform preserves the self-similarity scaling property, which is the inherent characteristic feature of deterministic chaos. The continuous wavelet transform has edge artifacts because the wavelet is completely localized in time. The cone of influence (COI) is the area in which the wavelet power caused by a discontinuity at the edge has dropped to $e^{-2}$ of the value to the edge. The statistical significance of the wavelet power can be assessed relative to the null hypotheses that the signal is generated by a stationary process with a given background power spectrum $\left(P_{k}\right)$ of the first-order autoregressive (AR1) process (Grinsted et. al., 2004):

$P_{k}=\frac{1-\alpha^{2}}{\left|1-\alpha e^{-2 i \pi k}\right|^{2}}$,

where $k$ is the Fourier frequency index.

The cross-wavelet transform is applied to two time series to identify the similar patterns that are difficult to assess from a continuous wavelet map. Cross-wavelet power 


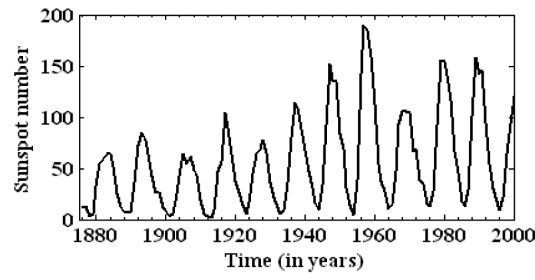

(a)

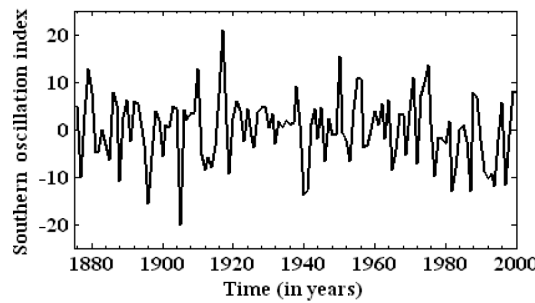

(c)

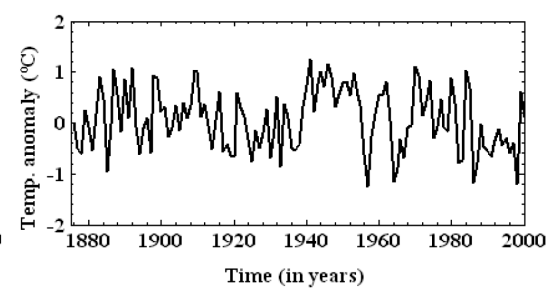

(b)

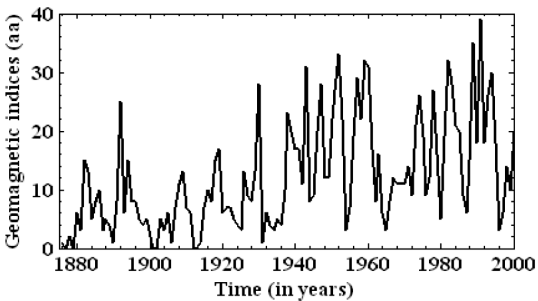

(d)

Figure 1. Time series data of (a) sunspot index, (b) the mean pre-monsoon temperature anomalies of the Western Himalayas (Yadav et al., 2004), (c) the Southern Oscillation Index (SOI) and (d) geomagnetic indices (aa indices) for the common period 1876-2000.

reveals areas with high common power. The cross-wavelet of two time series $x(t)$ and $y(t)$ is defined as $W^{X Y}=W^{x} W^{y^{*}}$, where "**" denotes the complex conjugate. The cross-wavelet power of two time series with background power spectra $P_{k}^{X}$ and $P_{k}^{Y}$ is given as

$D\left(\frac{\left|W_{n}^{X}(s) W_{n}^{Y^{*}}(s)\right|}{\sigma X \sigma Y}<p\right)=\frac{Z_{v}(p)}{v} \sqrt{P_{k}^{X} P_{k}^{Y}}$,

where $Z_{v}(p)$ is the confidence level associated with the probability $p$ for a pdf defined by the square root of the product of the two $\chi^{2}$ distributions (Torrence and Compo, 1998). The wavelet power is $\left|W_{n}^{X}(s)\right|^{2}$ and the complex argument of $\left|W_{n}^{X}(s)\right|$ can be interpreted as the local phase. The crosswavelet analysis gives the correlation between the two time series as a function of the period of the signal and its time evolution with a $95 \%$ confidence level contour. The statistical significance is estimated using a red noise model.

Wavelet coherence is another important measure to assess how coherent the cross-wavelet spectrum transform is in time-frequency space. The wavelet coherence of two time series is defined as (Torrence and Webster, 1999)

$R_{n}^{2}(s)=\frac{\left|S\left(s^{-1} W_{n}^{X Y}(s)\right)\right|^{2}}{S\left(s^{-1}\left|W_{n}^{X}(s)\right|^{2}\right) \cdot S\left(s^{-1}\left|W_{n}^{Y}(s)\right|^{2}\right)}$

where $S$ is a smoothing operator. The smoothing operator is written as $S(W)=S_{\text {scale }}\left(S_{\text {time }}\left(W_{n}(s)\right)\right)$, where $S_{\text {scale }}$ denotes smoothing along the wavelet scale axis and $S_{\text {time }}$ smoothing in time. Here, for the Morlet wavelet, the smoothing operator is

$$
\begin{aligned}
\left.S_{\text {time }}(W)\right|_{s} & =\left(W_{n}(s) \cdot c_{1}^{\frac{-t^{2}}{2 s^{2}}}\right), \\
\left.S_{\text {time }}(W)\right|_{s} & =\left(W_{n}(s) \cdot c_{2} \Pi(0.6 s)\right)_{n} \mid,
\end{aligned}
$$

where $c_{1}$ and $c_{2}$ are normalization constants and $n$ is the rectangle function. The factor of 0.6 is the empirically determined scale decorrelation length of the Morlet wavelet (Torrence and Compo, 1998). The statistical significance level of the wavelet coherence is estimated using the Monte Carlo methods (Grinsted et al., 2004).

\section{Results and discussion}

We analyzed the data sets spanning over the period of 18762000 using the PCA, SSA, and wavelet spectral analyses. Figure 1 shows four time series: (1) the smoothed sunspot number representing solar activities; (2) geomagnetic (aa indices); (3) the Troup Southern Oscillation Index (SOI) for the study of ENSO, and (4) the Western Himalayan temperature variability record, which are analyzed in the present work. From visual inspection it is apparent from Fig. 1 that both WH and SOI data show an irregular and random pattern, while sunspot numbers have a quasi-cyclic character. Furthermore, the WH tree-ring record also exhibits distinct temperature variability but nonstationary behavior at different scales. This variability might be suggestive of coupled global ocean-atmospheric dynamics or some other factors, such as deforestation, anthropogenic, or a high latitudinal influence (Yadav et al., 2004).

Hence it is quite difficult to differentiate such a complex climate signal visually, and difficult to infer any clear oscillation without the help of powerful mathematical methods. For 

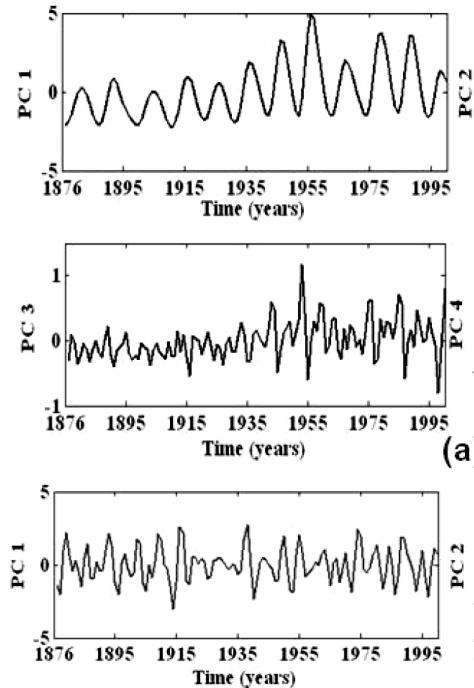

(a)
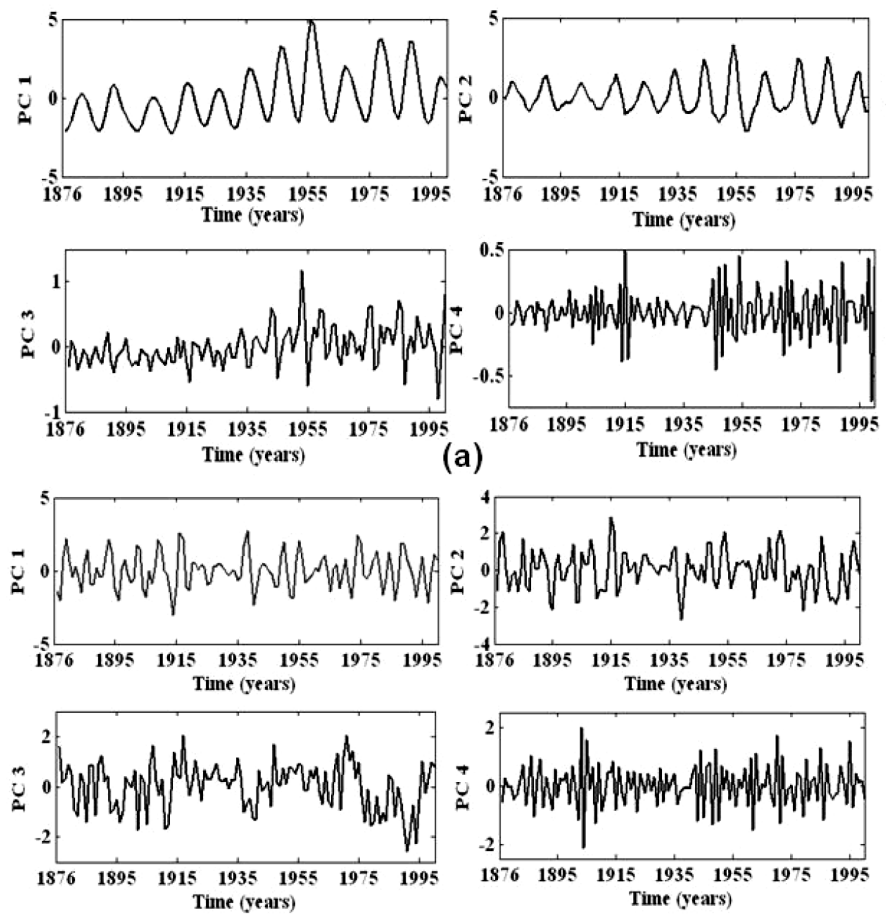

(c)
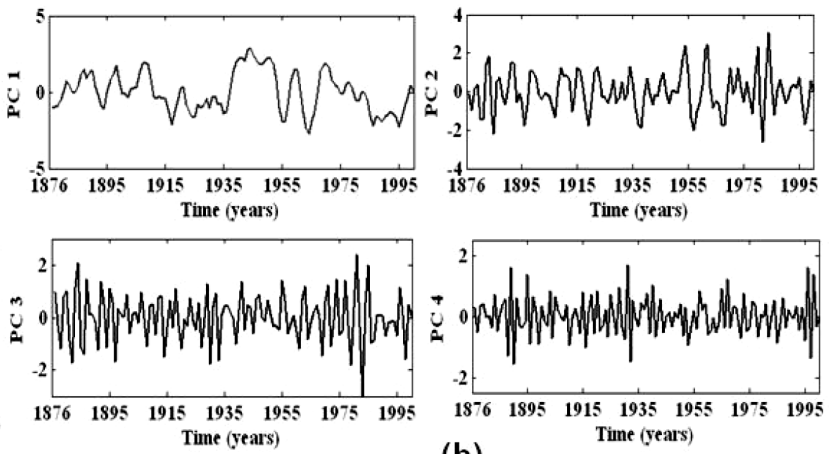

(b)
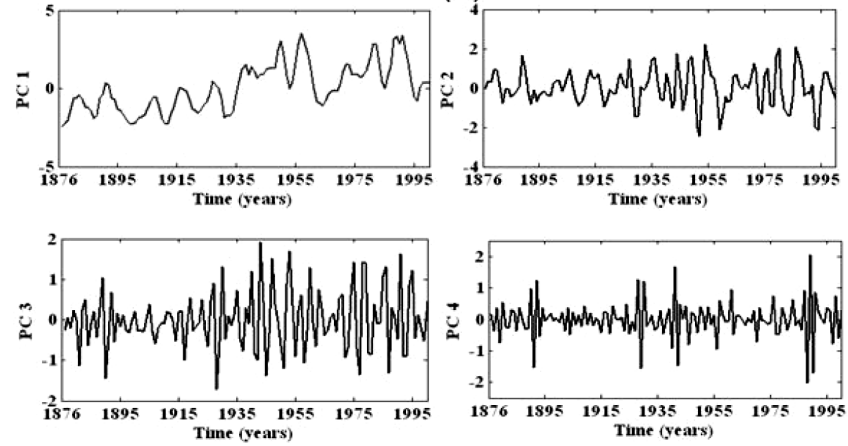

(d)

Figure 2. First four principal components (PCs 1-4) for time series: (a) sunspot numbers, (b) the mean pre-monsoon temperature anomalies of the Western Himalayas, (c) SOI index and (d) geomagnetic indices (aa indices) for the period 1876-2000.

identification of any oscillatory components and understanding of the climatic variations on regional and global scales, we have applied PCA, SSA, and wavelet analysis. Figure 2 shows the principal components (PCs) for the first four eigen triples (PC1, PC2, PC3, PC4) for the given data sets. Figure 3 shows the power spectra of the principal components (PCs) for the four data sets shown in Fig. 2. From Fig. 3, it is observed that the power spectra of PCs 1-4 for the sunspot data exhibit high power at 124,11 , and 4-2.8 years. The presence of a high solar signal at 124 years indicates the quasistable oscillatory components in the data. The power spectra of geomagnetic data also show the presence of strong signals at $124,10-11$, and 4-2 years, suggesting a strong link of solar-geomagnetic activity. The power spectra of WH temperature data show strong high power at $\sim 62,32$ $35,11,5$, and $2-3$ years, suggesting a strong combined influence of global ocean-atmospheric circulation, and solargeomagnetic and ENSO effects on the Indian climate system. Climate cycles of 50-70 years have been widely reported in various ocean and atmospheric phenomena (Ogurtsov et al., 2002; Tiwari, 2005). Schlesinger and Ramankutti (1994) and Minobe (1997) have reported similar 55-70-year interdecadal oscillations in global mean temperature. Dominant amplitudes corresponding to 62- and 32-35-year periodicities may, therefore, be linked to the Atlantic Multi-decadal Oscillation (AMO) of ocean-atmospheric circulations. The 11 -year peak is a well-known solar signal, while the 2-5-year periods apparently fall in the ENSO frequency band. These results could be better confirmed by applying the mathematical tools of SSA and wavelet analyses.

To explore the stationary characteristics of these peaks obtained by the PCA, we have applied the Morlet-based wavelet transform approach (Holschneider, 1995; Foufoula-Georgiou and Kumar, 1995; Torrence and Compo, 1998; Grinsted et al., 2004). The wavelet spectrum identifies the main periodicities in the time series and helps to analyze the periodicities with respect to time. Figure 4 shows the wavelet spectrum for the (a) smoothed sunspot number for solar activity (SSN), the (b) Western Himalayan (WH) temperature variability record, (c) geomagnetic activity, and the (d) Troup Southern Oscillation Index (SOI). From the wavelet spectrum of sunspot time series (Fig. 4a), the signal near 11 years is the strongest feature and is persistent during the entire series, indicating the non-stationary behavior of the sunspot time series. The wavelet spectrum of SOI (Fig. 4c) shows strong amplitudes. However, due to the non-stationary (time-variant) character of the time series, the observed spectral peaks (power) split in the interval of 2-8 years. The wavelet power spectrum of the Western Himalayan temperature variability (Fig. 4b) reveals significant power concentration on inter-annual timescales of 3-5 years and at an 11-year solar cycle. A dominant amplitude mode is also seen in the low-frequency range at around 35-40 years (at periods 1930-1980) corresponding to AMO cycles. Our result agrees well with the results of other cli- 


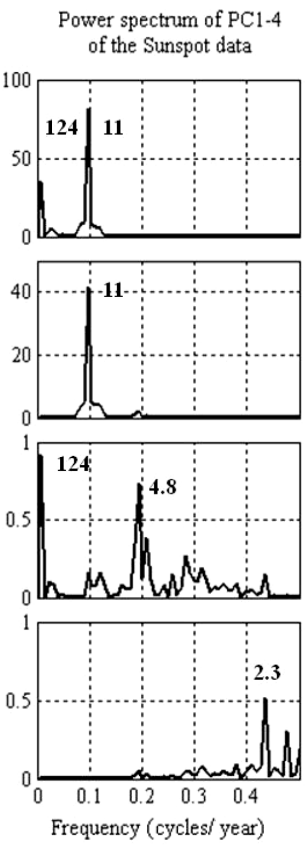

(a)

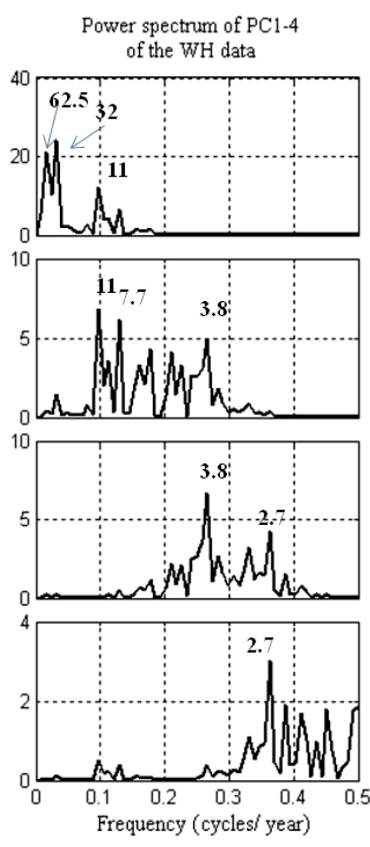

(b)

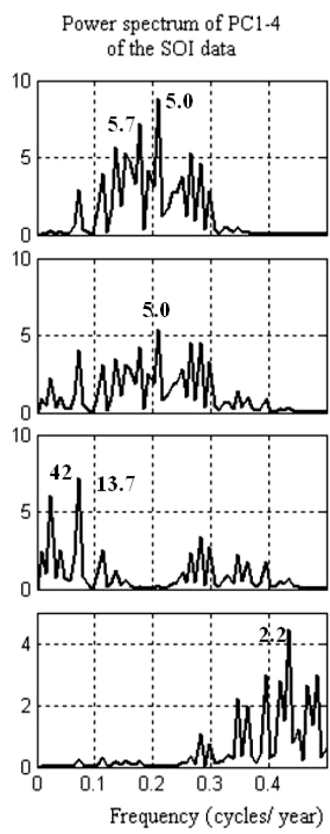

(c)

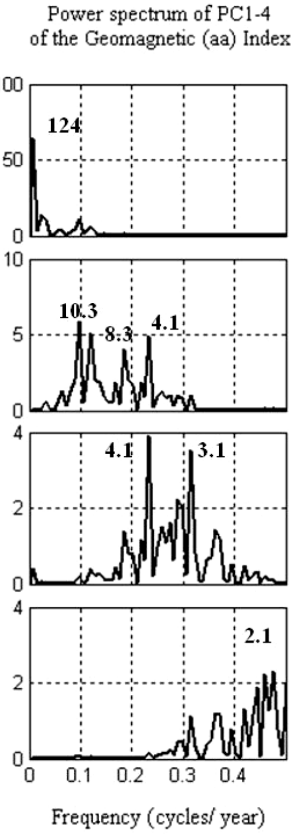

(d)

Figure 3. Power spectra of the first four principal component (PCs) (PCs 1-4 shown in Fig. 2) for all the data sets with their significant periodicities at 124, 11, 4 and 2.8 years indicated in bold letters.

mate reconstructions (Mann et. al., 1995) from tree rings and other proxies. The observed variability in AMO periodicity has also been reported in other tree-ring records (Gray et al., 2004). The statistical significance of the wavelet power spectrum is tested by a Monte Carlo method (Torrence and Compo, 1998). The WH spectra depicting statistically significant powers above the $95 \%$ significance level at around 5, 11 and 33 years suggests the possible imprint of sunspotgeomagnetic and ENSO phenomena on the tree-ring data. On shorter timescales, the wavelet power spectrum of the geomagnetic record (Fig. 4d) also reveals statistically significant power at around 2-, 4-8-, and 11-year periods.

In order to have better visualization of similar periods in two time series and for the interpretation of the results, the cross-wavelet spectrum has been applied. Figure 5 shows the cross-wavelet spectrum of the (a) SSN-WH temperature data, (b) WH data-SOI, and (c) SSN-SOI data. The contours (dark black lines) are the enclosing regions where crosswavelet power is significantly higher, at $95 \%$ confidence levels. The wavelet cross-spectra of WH-SSN (Fig. 5a) show a statistically significant high power over a period of 18951985 in a 8-16-year band. It is seen that in the WH-SOI cross-spectra (Fig. 5b), the high power is observed at a 2$4-$ year band and at 8-16 years as well. The SSN-SOI spectra (Fig. 5c) show a strong correlation at an 11-year solar cycle, which is stronger during 1910-1950 and 1960-2000 (Rigozo et al., 2002, 2003), suggesting the strongest El Niño and La Niña events, indicating solar modulation on ENSO
(Kodera and Kuroda, 2005; Kryjov and Park, 2007). These results show a good correspondence in response to growth of the tree-ring time series during the intense solar activity. Hence the results strongly support the possible origin of these periodicities from solar and ENSO events. The interesting conclusion from Fig. 5 is that WH-sunspot connections are strong at 11 years, and ENSO-sunspot connections also exhibit strong power around 11 years; the WH-ENSO connections are spread over three bands, $2-4,4-8$, and 816 years, covering the solar cycle and its harmonics; the WH-geomagnetic exhibits strong connections around 2-4, $4-6,11$, and 35-40 years, indicating the influence of solargeomagnetic activity on Indian temperature.

Singular spectral analysis (SSA) is performed for all four data sets with a window length of 40 . The SSA spectra with 40 singular values and their corresponding reconstructed series (varying from RCs 1 to 15 in some cases) are plotted as shown in Figs. 6 and 7. The important insights from SSA spectra are the identification of gaps in the eigenvalue spectra. As a rule, the pure noise series produces a slowly decreasing sequence of singular values. The explicit plateau in the spectra represents the ordinal numbers of paired eigen triples. Eigen triples 2-3 for the sunspot data correspond to the 11-year period; eigen triples for 1-2, 3-5, 6-10, and 1114 for the WH temperature data are related to harmonics with specific periods (periods 33-35, 11, 5, 2 years); eigen triples for $2-5,6-9$, and $10-13$ for the geomagnetic data are related to periods of 11,5 , and 2 years. The eigen triples for the SOI 


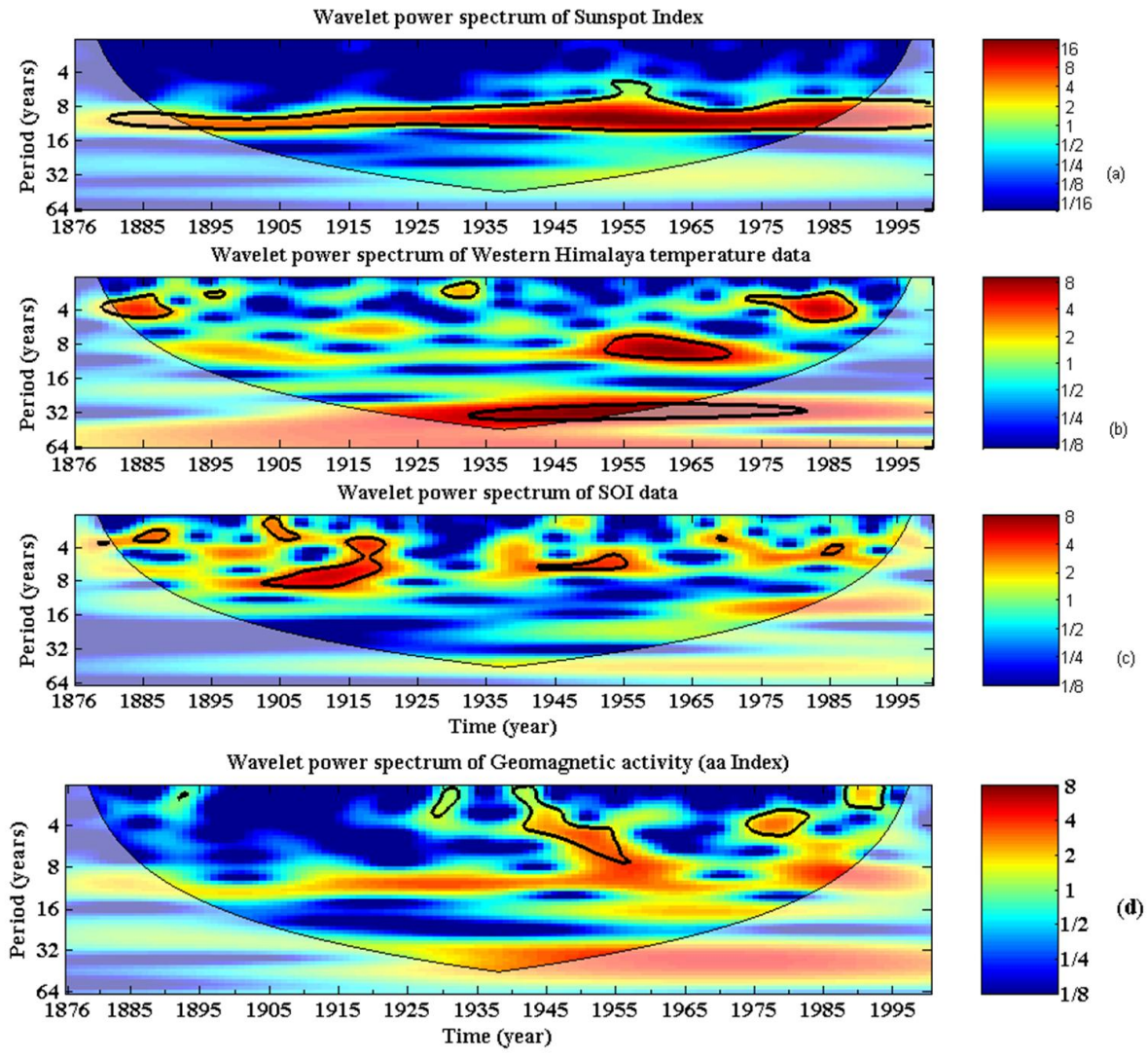

Figure 4. Wavelet power spectrum of (a) sunspot number, (b) Western Himalayan temperature data, (c) Southern Oscillation Index (SOI) and (d) geomagnetic activity (aa indices) with the cone of influence (lighter shaded smooth curve) and black lines indicating significant power on the $95 \%$ level compared to red noise based on the first-order auto-regressive (AR(1)) coefficient. The legend on the right indicates the cross-wavelet power.

data represent $\sim 5-7$ - and 2-year periods. In order to assess periodicities, the periodogram and the wavelet power spectra are plotted using the SSA reconstructed data (SSA-RC) (Fig. 8). From Fig. 8, the periodogram of SSA-RC of SSN and geomagnetic data shows strong power at $\sim 120$ and 10 11 years; the SOI data show strong peaks at $6-9$ and 3 years, and WH data show strong power at $\sim 32, \sim 10-11$, and $3-$ 5 years. The wavelet spectra for all the SSA-RC data confirm the results, except for the periods at $\sim 120$ years, which are beyond the maximum scaling period chosen for the present wavelet. The coherency plot of the SSA-RC data sets (Fig. 9) indicates a significant power at 33,11 , and $2-7$ years in the WH temperature record, suggesting the possible influences of sunspot-geomagnetic activity and ENSO through teleconnection and hence a significant role of these remote internal oscillations of the atmosphere-ocean system in the Indian climate system. Researchers have attributed these phenomena to internal ocean dynamics and involve ocean atmospheric coupling as well as variability in the strength of thermohaline circulations (Knight et al., 2005; Delworth and Mann, 2000).
In general our result agrees well with earlier findings in the sense that statistically significant global cycles of coupled effects of sunspot-geomagnetic activity and ENSO are present in the land-based temperature variability record. However, there are certain striking features in the spectra that need to be emphasized regarding the Western Himalayan temperature variability: (i) inter-annual cycles in a period range of 38 years corresponding to ENSO in the wavelet spectra exhibit intermittent oscillatory characteristics throughout the large portion of the record (Fig. 4); (ii) the 11-year solar cycle in the cross-wavelet spectrum of SSN and SOI (Fig. 5) indicates the solar modulation in the ENSO phenomena (Kodera and Kuroda, 2005; Kryjov and Park, 2007); and (iii) the high amplitude at 11 years in the time interval 1900-1995 with a strong intensity from 1900 to 1995 shows a good correspondence to the high temperature variability for the interval of high solar-geomagnetic activity. The multi-decadal (30-40year) periodicity identified here in the Western Himalayan tree-ring temperature record matches with North Atlantic sea surface temperature variability, implying that the temperature variability in the Western Himalayas is not a regional phenomenon but a globally teleconnected climate phenomenon 


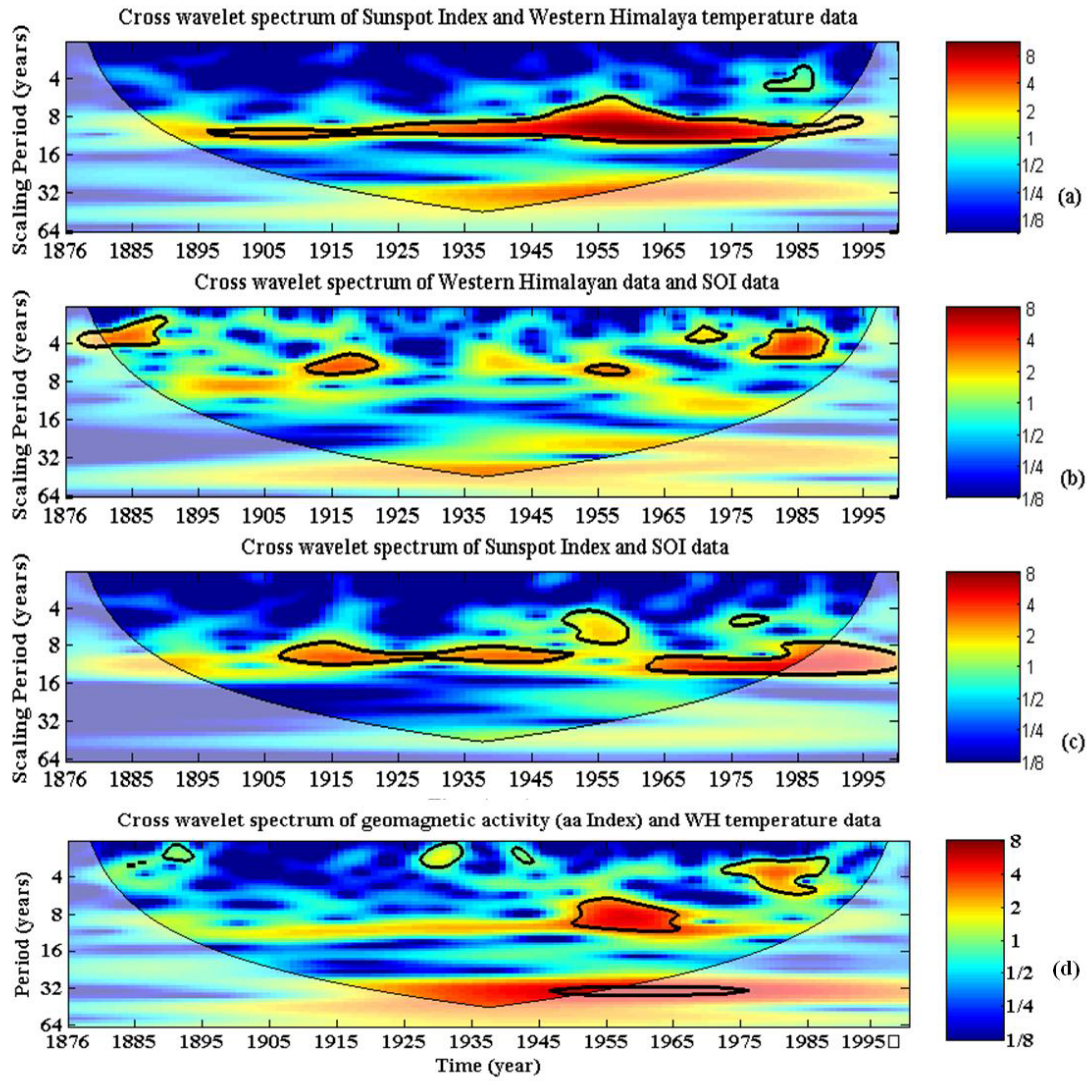

Figure 5. Cross-wavelet spectrum between (a) sunspot number-Western Himalayan data, (b) Western Himalayan-Southern Oscillation Index, (c) sunspot number-Southern Oscillation Index, and (d) geomagnetic aa indices-Western Himalayan data with the cone of influence (lighter shaded smooth curve) and black lines indicating significant power on a $95 \%$ level compared to red noise based on the AR(1) coefficient. The legend on the right indicates the cross-wavelet power.
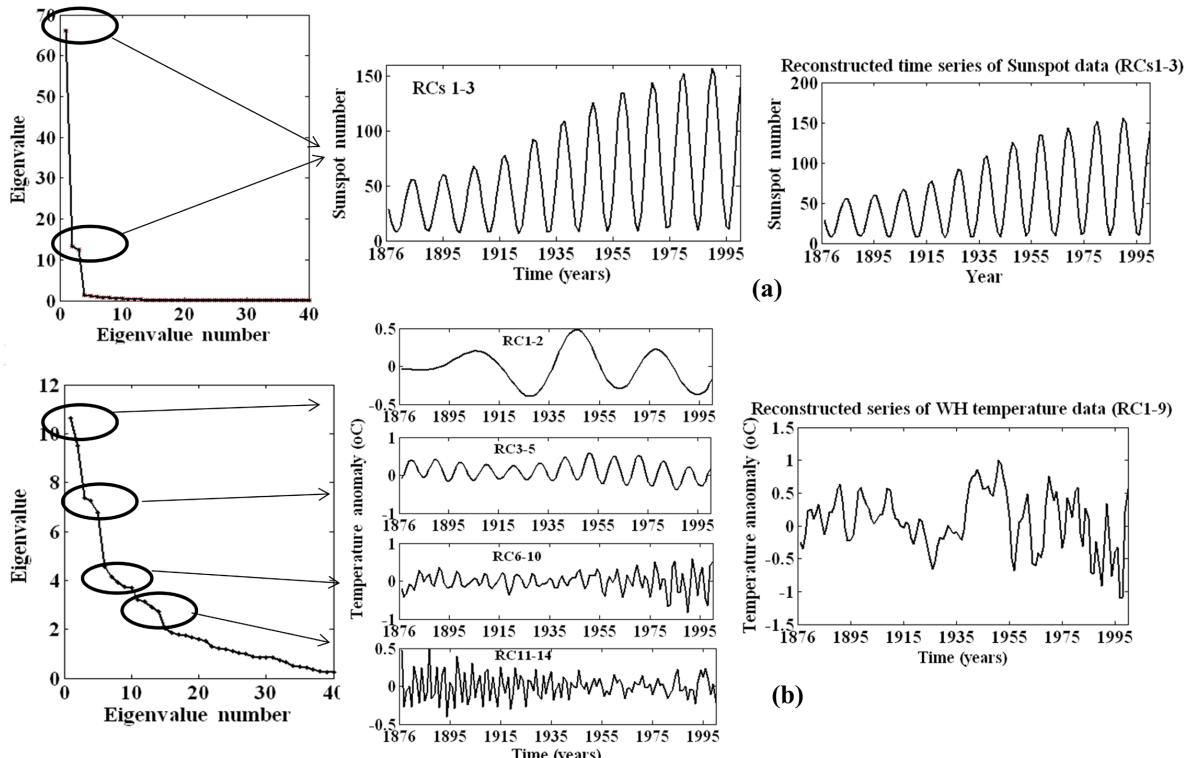

(a)

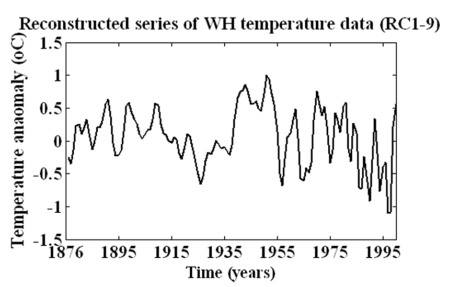

(b)

Figure 6. Singular spectra with their SSA decomposed components and their reconstructed time series for (a) sunspot number and (b) Western Himalayan temperature data. 

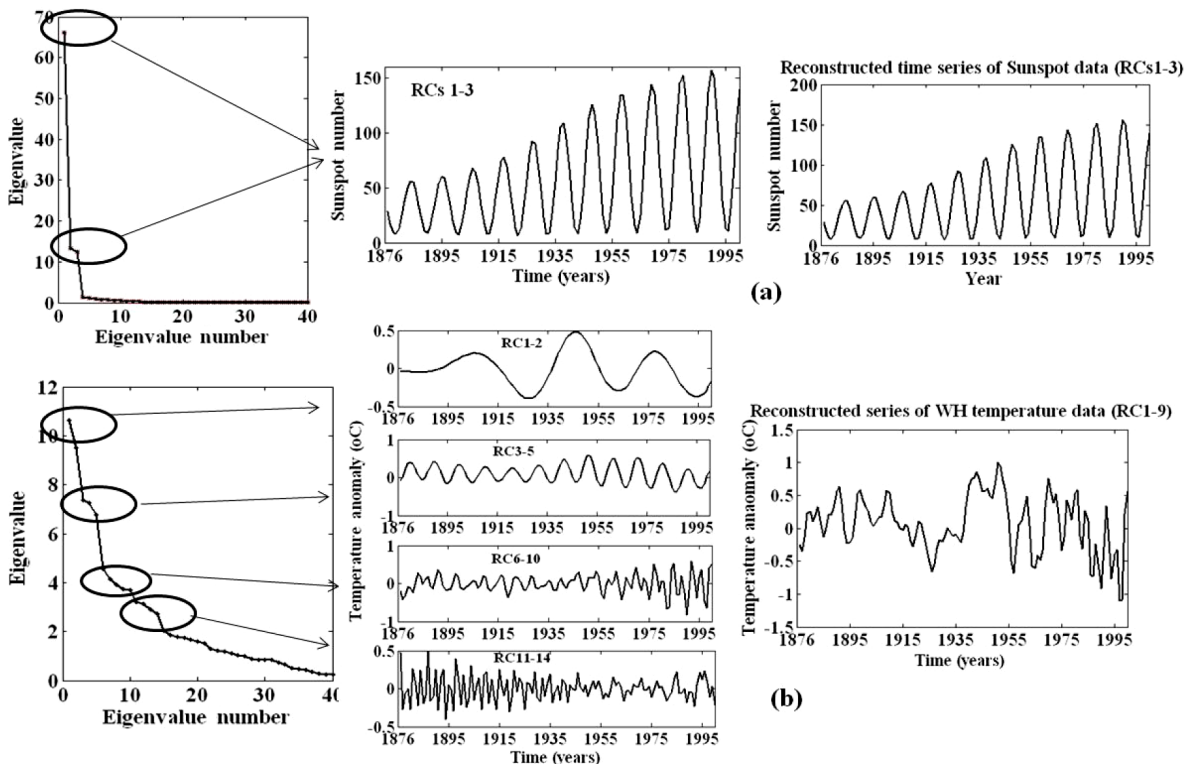

(a)

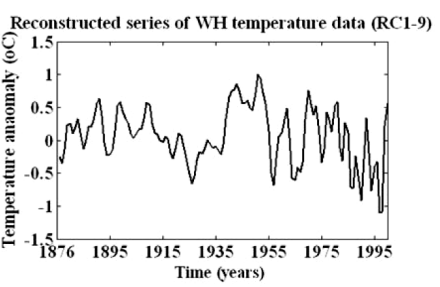

(b)

Figure 7. Singular spectra with their SSA decomposed components and their reconstructed time series for (a) SOI and (b) geomagnetic activity (aa indices).
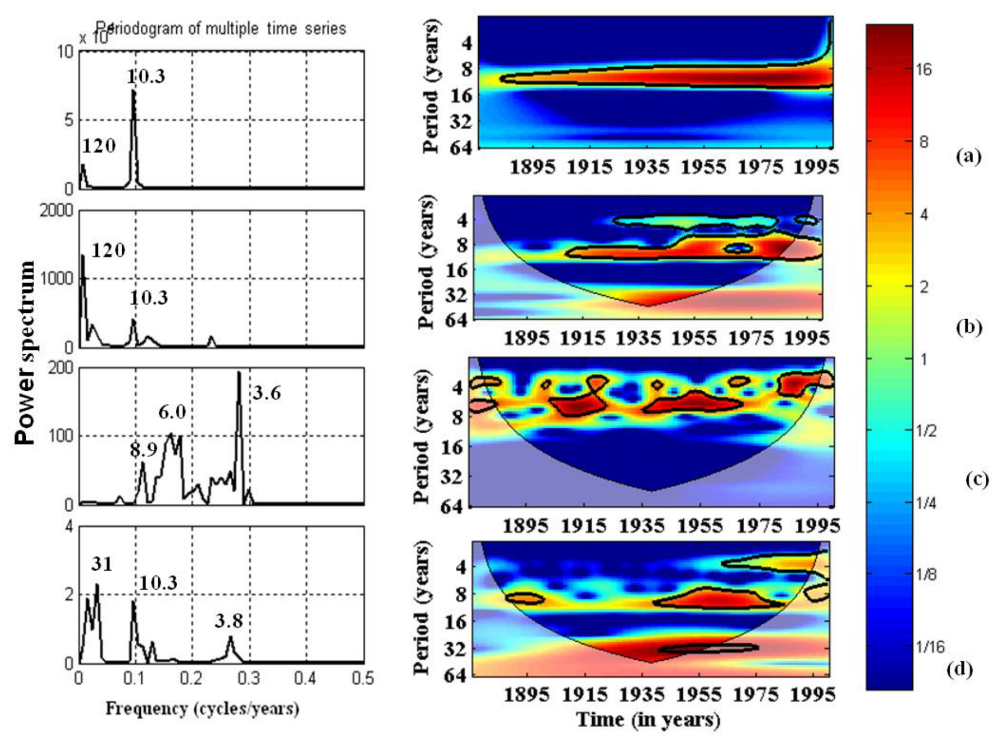

Figure 8. Power spectrum and wavelet power spectrum of SSA reconstructed (a) sunspot data, (b) geomagnetic indices (aa index), (c) SOI, and (d) the Western Himalayan temperature data, with the cone of influence (lighter shaded smooth curve) and black lines indicating significant power on the $95 \%$ level compared to red noise based on the AR(1) coefficient. The legend on the right indicates the cross-wavelet power.

associated with the global ocean-atmospheric dynamics system (Tiwari and Srilakshmi, 2009; Delworth et al., 1993; Stocker, 1994). The coupled ocean-atmosphere system appears to transport energy from the hot equatorial regions towards Himalayan territory in a cyclic manner. These results may provide constraints for modeling of climatic variability over the Indian region and ENSO phenomena associated with the redistribution of temperature variability. The solar- geomagnetic effects play a major role in abnormal heating of the land surface, thereby indirectly affecting the atmospheric temperature gradient between the land-ocean coupled systems. In the present work, the connections between solar-geomagnetic activity and ENSO on the WH time series are found to be statistically significant, especially when they are studied over contrasting epochs of, respectively, high and low solar activity. The correlation plots for the SSA-RC data 


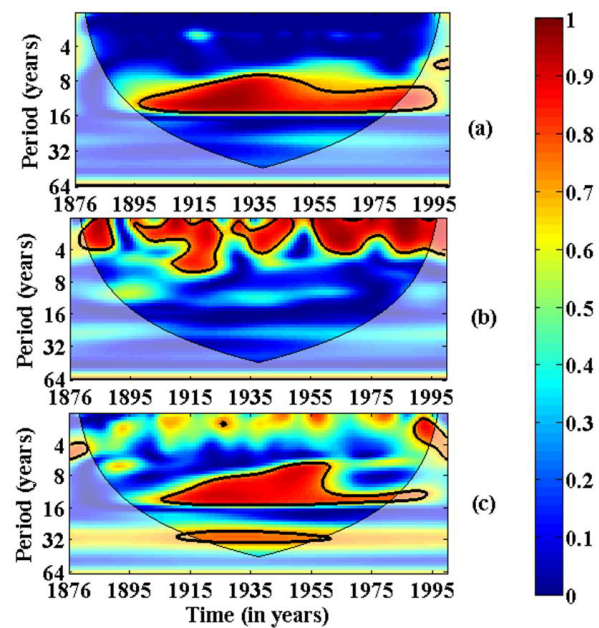

Figure 9. Squared wavelet coherence plotted for the SSA reconstructed time series between (a) WH-SSN, (b) WH-SOI, and (c) the WH-aa index, with the cone of influence (lighter shaded smooth curve) and black lines indicating significant power on the $95 \%$ level compared to the red noise based on the AR(1) coefficient.

sets of WH-sunspot, WH-aa index, WH-SOI, and sunspotaa index are plotted in Fig. 10. One can notice that there is a correlation plot for the geomagnetic-sunspot activity with a maximum correlation value at a 1-year lag, suggesting the strong influence of sunspot and geomagnetic forcing on one another. The cross-correlation plot for the WH data and the SOI represents a maximum value at zero lag. The correlation plot for the WH-sunspot and WH-geomagnetic indices exhibits almost identical results, suggesting the possible impact of solar activities on the Indian temperature variability.

The net effect of solar activity on temperature record therefore appears to be the result of cooperating or counteracting influences of Earth's magnetic activity on the shorter and longer periods, depending on the indices used; scale interactions, therefore, appear to be important. Nevertheless, the link between Indian climate and solar-geomagnetic activity emerges as having strong evidence; next is the ENSO-solar activity connection.

\section{Conclusions}

In the present paper, we have studied and identified the periodic patterns from the published Indian temperature variability records using the modern spectral methods of singular spectral analysis (SSA) wavelet methods. The application of wavelet analysis for the SSA reconstructed time series, along with the removal of noise in the data, identifies the existence of high-amplitude, recurrent, multi-decadal scale patterns that are present in Indian temperature records. The power spectra of WH temperature data show a strong high power at $\sim 62,32-35,11,5$ and $2-3$ years, suggesting a strong influence of solar-geomagnetic-ENSO effects
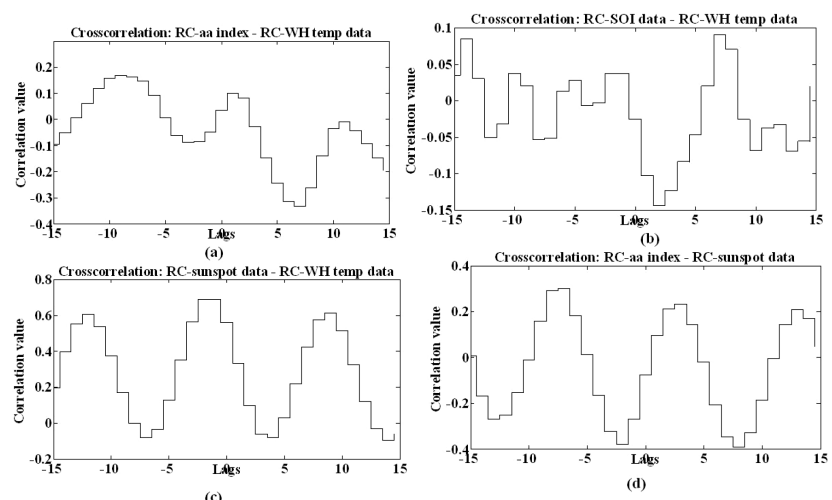

Figure 10. Cross-correlation of SSA reconstructed time series of (a) aa index-Western Himalayan (WH) temperature data, (b) SOIWH temperature data, (c) sunspot-WH data, and (d) aa indexsunspot data.

on the Indian climate system. The presence of a dominant amplitude at 33-year cycle periodicity corresponds to Atlantic Multidecadal Oscillation (AMO) cycles. It also suggests the Sun-temperature variability, probably involving the induced changes in the basic state of the atmosphere. The 30-40-year periodicity in the Western Himalayan treering temperature record matches with the global signal of the coupled ocean-atmospheric oscillation (Delworth et al., 1993; Stocker, 1994), implying that the temperature variability in the Himalayas is not a regional phenomenon but seems to be teleconnected phenomena with the global ocean-atmospheric climate system. The coherency plots of the SSA reconstructed WH-sunspot, WH-geomagnetic, and WH-SOI data sets show strong spectral signatures in the whole record, confirming the possible influences of sunspotgeomagnetic activities and ENSO through teleconnection and hence the significant role of these remote internal oscillations of the atmosphere-ocean system in the Indian temperatures. We conclude that the signature of solar-geomagnetic activity affects the surface air temperatures of the Indian subcontinent. However, long data sets from the different sites on the Indian subcontinent are necessary to identify the influences of the 120-year solar-geomagnetic cycles.

\section{Data availability}

The data on the Western Himalayan data was given to us by Dr. Ram Ratan Yadav of Birbal Sahni Institute of Palaeobotany, India. The data plot was given in his publication (Yadav et al., 2004).

Acknowledgements. The authors are extremely thankful to the Editor Stéphane Vannitsem and the anonymous reviewers for their professional comments, meticulous reading of the manuscript, and valuable suggestions to improve the manuscript. The authors 
thank Dr. Ram Ratan Yadav, Birbal Sahni Institute of Palaeobotany, India, for providing the Western Himalayan data. The authors acknowledge Prof. Francisco Javier Alonso of the University of Extremadura for using the SSA routine in a MATLAB environment. We are thankful to Dr. Alask Grinsted and his colleagues for providing the wavelet software package. The first author acknowledges the Head, University Centre for Earth \& Space Sciences, University of Hyderabad, for providing the facilities to carry out this work. Rama Krishna Tiwari is grateful to DAE for a RRF (Rajaramanna Fellowship).

Edited by: S. Vannitsem

Reviewed by: three anonymous referees

\section{References}

Alonso, F. J., Castillo, J., and Pintado, P.: Application of Singular Spectrum Analysisto the Smoothing of Raw Kinematic Signals, J. Biomech., 38, 1085-1092, 2005.

Appenzeller, C., Stocker, T. F., and Anklin, M.: North Atlantic Oscillation Dynamics Record in Greenland Ice Cores, Science, 282, 446-449, 1998.

Barnett, T. P., Dumeil, L., Schlese, U., and Roeckner, L.: The effect of Eurasian snow cover on regional and global climate variations, J. Atmos. Sci., 48, 661-685, 1989.

Benestaed, R. E. and Schmidt, G. A.: Solar trends and global warming, J. Geophys. Res., 114, D1401, doi:10.1029/2008JD011639, 2009.

Bhattacharyya, A. and Chaudhary, V.: Late-summer temperature reconstruction of the Eastern Himalayan Region based on tree-ring data of Abies densa, Arct. Antarct. Alp. Res., 35, 196-202, 2003.

Bhattacharyya, A. and Yadav, R. R.: Dendrochronological reconnaissance of Pinus wallichiana to study glacial behaviour in the western Himalaya, Current Science, 70, 739-744, 1996.

Bhatacharyya, A., LaMarche, V. C., and Telewski, F. W.: Dendrochronological reconnaissance of the conifers of Northwest India, Tree-Ring Bull., 48, 21-30, 1988.

Bhattacharyya, A., Yadav, R. R., Borgaonkar, H. P., and Pant, G. B.: Growth ring analysis of Indian tropical trees: Dendroclimatic potential, Current Science, 62, 736-741, 1992.

Bhattacharyya, A., Shah, S. K., Santosh, K., and Chaudhary, V.: Would tree-ring data of Betula utilis be potential for the analysis of Himalayan Glacial fluctuations?, Current Science, 91, 754761, 2006.

Borgaonkar, H. P., Pant, G. B., and Rupa Kumar, K.: Ring width variations in Cedrus deodara and its climatic response over the Western Himalaya, Int. J. Climatol., 16, 1409-1422, 1996.

Broomhead, D. S. and King, G. P.: Extracting qualitative dynamics from experimental data, Physica D, 20, 217-236, 1986.

Budyko, M. I.: The effect of solar radiation variations on the climate of the Earth, Tellus, 21, 611-619, 1969.

Chaudhary, V., Bhattacharyya, A., and Yadav, R. R.: Tree-ring studies in the Eastern Himalayan region: Prospects and problems, IAWA - International Association of Wood Anatomists, 20, 317324, 1999.

Chowdary, J. S., Gnanseelan, C., Vaid, B. H., and Salvekar, P. S.: Changing trends in the tropical Indian Ocean SST during La Nina years, Geophys. Res. Lett., 33, L18610, doi:10.1029/2006GL026707, 2006.

Chowdary, J. S., John, N., and Gnanseelan, C.: Interannual variability of surface air-temperature over India: impact of ENSO and Indian Ocean Sea surface temperature, Int. J. Climatol., 34, 416429, 2014.

Cole, J. E., Fairbanks, R. G., and Shen, G. T.: Recent variability in the Southern Oscillation: Isotopic results from a Tarawa Atoll coral, Science, 260, 1790-1793, 1993.

De Freitas, C. and Mclean, J.: Update of the Chronology of Natural Signals in the Near Surface Mean Global Temperature Record and the Southern Oscillation Index, Int. J. Geosci., 4, 234-239, 2013.

Delworth, T. and Mann, M.: Observed and Stimulated multideacadl variability in the Northern Hemisphere, Clim. Dynam., 16, 661676, 2000.

Delworth, T., Manabe, S., and Stouffer, R. J.: Interdecadal variations of the thermohaline circulation in a coupled oceanatmosphere model, J. Climate, 6, 1991-2011, 1993.

El-Borie, M. A. and Al-Thoyaib, S. S.: Can we use the aa geomagnetic activity index to predict partially the variability in global mean temperature, J. Phys. Sci., 1, 67-74, 2006.

El-Borie, M. A., Al. Thoyaib, S. S, and Al-Sayed, N.: The possible role of solar activity in variability of global mean temperature, in: The 2nd International conference of Physics and Material Science, Vol. 1, 302-310, 2007.

El-Borie, M. A., Shafik, E., Abdel-Halim, A. A., and El-Monier, S.: Spectral analysis of solar variability and their possible role on the global warming (1880-2008), J. Environ. Protect., 1, 111-120, 2010.

Feng, S. H., Kaufman, D., Yoneji, S., Nelson, D., Shemesh, A., Huang, Y., Tian, J., Bond, G., Benjamin, C., and Brown, T.: Cyclic Variation and Solar Forcing of Holocene Climate in the Alaskan Subarctic, Science, 301, 1890-1893, 2003.

Foufoula-Georgiou, E. and Kumar, P. (Eds.): Wavelets in Geophysics, Academic San Diego, San Diego, California, 373 pp., 1995.

Friis, C. E. and Lassen, K.: Length of the Solar Cycle: An Indicator of Solar Activity Closely Associated with Climate, Science, 254, 698-700, 1991.

Friis, C. E. and Svensmark, H.: What do we really know about the sun-climate connection?, Adv. Space Res., 20, 913-921, 1997.

Frohlich, C. and Lean, J.: Solar radiative output and its Variability: Evidence and Mechanisms, Astron. Astropys. Rev., 12, 273-320, 2004.

Golyandina, N., Nekrutkin, V. V., and Zhigljavski, A. A.: Analysis of Time Series Structure: SSA and Related Techniques, CRC Press, Boca Raton, 2001.

Gray, L. J., Beer, J., Geller, M., Haigh, J. D., Lockwood, M., Matthes, K., Cubasch, U., Fleitmann, D., Harrison, G., Hood, L., Luterbacher, J., Meehl, G. A., Shindell, D., van Geel, B., and White, W.: Solar influences on climate, Rev. Geophys., 48, RG4001, doi:10.1029/2009RG000282, 2010.

Gray, S. T., Graumlich, L. J., Betancourt, J. L., and Pederson, G. T.: A tree-ring based reconstruction of the Atlantic Multidecadal Oscillation since 1567 A.D., Geophys. Res. Lett., 31, L12205, doi:10.1029/2004GL019932, 2004. 
Gray, W. M., Sheaffer, J. D., and Knaff, J. A.: Hypothesized mechanism for stratospheric QBO influence on ENSO variability, Geophys. Res. Lett., 19, 107-110, 1992.

Grinsted, A., Moore, J. C., and Jevrejeva, S.: Application of the cross wavelet transform and wavelet coherence to geophysical time series, Nonlin. Processes Geophys., 11, 561-566, doi:10.5194/npg-11-561-2004, 2004.

Gu, D. and Philander, S. G. H.: Secular changes of annual and interannual variability in the tropics during the past century, J. Climate, 8, 864-876, doi:10.1016/S0273-1177(97)00499-7, 1995.

Holschneider, M.: Wavelets: An Analysis Tool, Oxford University Press, New York, 1-455, 1995.

Horel, J. D. and Wallance, J. M.: Planetary-scale atmospheric Phenomena associated with the Southern Oscillation, Mon. Weather Rev., 109, 813-829, 1981.

Hughes, M. K.: Dendroclimatic evidence from the Western Himalaya, in: Climate since AD 1500, edited by: Bradlay, R. S. and Jones, D., Routledge, London, 15-431, 1992.

Jevrejeva, S., Moore, J. C., and Grinsted, A.: Influence of the Arctic Oscillation and El Niño-Southern Oscillation (ENSO) on ice conditions in the Baltic Sea: The wavelet approach, J. Geophys. Res., 108, 4677, doi:10.1029/2003JD003417, 2003.

Kasatkina, E. A., Shumilov, O. I., and Krapiec, M.: On periodicities in long term climatic variations near $68^{\circ} \mathrm{N}, 30^{\circ} \mathrm{E}$, Adv. Geosci., 13, 25-29, doi:10.5194/adgeo-13-25-2007, 2007.

Kiladis, G. N. and Diaz, F. H.: Global Climatic Anomalies Associated with Extremes in the Southern Oscillation, J. Climate, 2, 1069-1090, 1989.

Knight, J. R., Allan, R. J., Folland, C. K., Vellinga, M., and Mann, M. E.: A signature of persistent natural thermohaline circulation cycles in observed climate, Geophys. Res. Lett., 32, L20708, doi:10.1029/2005GL024233, 2005.

Kodera, K. and Kuroda, Y.: A possible mechanism of the spatial structure of the North Atlantic Oscillation, J. Geophys. Res., 110, D02111, doi:10.1029/2004JD005258, 2005.

Kothwale, D. R., Munot, A. A., and Krishna Kumar, K.: Surface air temperature variability over India during 1901-2007 and its association with ENSO, Clim. Res., 42, 89-104, doi: 10.3354/cr00857, 2010

Kryjov, V. N. and Park, C.-K.: Solar modulation of the ElNino/Southern Oscillation impact on the Northern Hemisphere annular mode, Geophys. Res. Lett., 34, L10701, doi:10.1029/2006GL028015, 2007.

Lean, J., Beer, J., and Bradley, R.: Reconstruction of solar irradiance since 1610: Implications for climate change, Geophys. Res. Lett., 22, 3195-3198, 1995.

Lean, J. L. and Rind, D. H.: How natural and anthropogenic influences alter global and regional surface temperatures: 1889 to 2006, J. Geophys. Res., 35, L18701, doi:10.1029/2008GL034864, 2008.

Mann, M. E., Park, J., and Bradley, R. S.: Global interdecdal and century-scale climate oscillations during the past 5 centuries, Nature, 378, 266-270, 1995.

Meehl, G. A., Arblaster, J. M., Matthes, K., Sassi, F., and Van Loon, H.: Amplifying the Pacific climate system response to a small 11-year solar cycle forcing, Science, 325, 1114-1118, 2009.

Mendoza, B., Perez-Enriquez, R., and Alvarez-Madrigal, M.: Analysis of solar activity conditions during periods of El Nino events, Ann. Geophys., 9, 50-54, 1991.
Minobe, S.: A 50-70 year climatic oscillation over the North Pacific and North America, Geophys. Res. Lett., 24, 683-686, 1997.

Mokhov, I. I., Eliseev, A. V., Handorf, D., Petukhov, V. K., Dethloff, K., Weishiemer, A., and Khvorostyanov, D. V.: North Atlantic Oscillation: Diagnosis and simulation of decadal variability and its long period evolution, Atmos. Ocean Phys., 36, 555-565, 2000.

Nicolson, S. E.: An analysis of the Enso signal in the tropical Atlantic and western Indian oceans, Int. J. Climatol., 17, 345-375, 1997.

Ogurtsov, M. G., Nagovitsyn, Y. A., Kocharov, G. E., and Jungner, H.: Long-period cycles of the Sun's activity recorded in direct solar data and proxies, Solar Physics, 211, 371-394, 2002.

Pant, G. B. and Rupa Kumar, K.: Climates of South Asia, John Wiley and Sons, Chichester, 320 pp., 1997.

Proctor, C. J., Baker, A., and Barnes, W. L.: A three thousand year record of North Atlantic Climate, Clim. Dynam., 19, 449-454, 2002.

Reid, G. C.: Solar irradiance variations and global Ocean Temperature, J. Geomag. Geoelectr., 43, 795-801, 1991.

Reid, G. C. and Gage, K. S.: The climatic impact of secular variations in solar irradiance, in: Secular Solar and geomagnetic Variations in the Last 10000 years, NATO AS Series, edited by: Stephenson, F. R. and Wplfendale, A. W., Kluwer, Dordrecht, 225-243, 1988.

Rigozo, N. R., Noredmann, D. J. R., Echer, E., Zanandrea, A., Gonzalez, W. D.: Solar variability effects studied by tree-ring data wavelet analysis, Adv. Space Res., 29, 1985-1988, 2002.

Rigozo, N. R., Vieira, L., Echer, E., and Nordemann, D. J. R.: Wavelet analysis of Solar-ENSO imprints in tree-ring data from Southern Brazil in the last century, Climatic Change, 60, 329340, 2003.

Rigozo, N. R., Nordeman, D. J. R., Echer, E., Vieira, L. E. A., Echer, M. P. S., and Prestes, A.: Tree-ring width wavelet and spectral analysis of solar variability and climatic effects on a Chilean cypress during the last two and a half millennia, Clim. Past Discuss., 1, 121-135, doi:10.5194/cpd-1-121-2005, 2005.

Rigozo, N. R., Nordeman, D. J. R., Silva, H. E., Echer, M. P. S., and Echer, E.: Solar and climate signal records in tree ring width from Chile (AD1587-1994), Planet. Space Sci., 55, 158-164, 2007.

Schlesinger, M. E. and Ramankutti, N.: An oscillation in the global climate system of period $65-70$ years, Nature, 367, 723-726, 1994.

Shah Santosh, K., Bhattacharyya, A., and Chaudhary, V.: Reconstruction of June-September Precipitation based on tree-ring data of Teak (Tectona grandis L.) from Hoshangabad, Madhya Pradesh, India, Dendrochronologia, 25, 57-64, 2007.

Steinhilber, F., Beer, J., and Frohlich, C.: Total solar irradiance during the Holocene, Geophys. Res. Lett., 36, L19704, doi:10.1029/2009GL040142, 2009.

Stocker, T. F.: The variable ocean, Nature, 367, 221-222, 1994.

Tiwari, R. K.: Geospectroscopy, Capital Publ. Co., New Delhi, p. 308, 2005.

Tiwari, R. K. and Srilakshmi, S.: Periodicities and non-stationary modes in tree ring temperature variability record of the Western Himlayas by multitaper and wavelet spectral analyses, Current Science, 97, 705-709, 2009.

Torrence, C. and Compo, G. P.: A practical guide to wavelet analysis, B. Am. Meteorol. Soc., 79, 61-78, 1998. 
Torrence, C. and Webster, P.: Interdecadal changes in the ESNOMonsoon System, J. Climate, 12, 2679-2690, 1999.

Tsonis, A. A., Elsner, J. B., Hunt, A. G., and Jagger, T. H.: Unfolding the relation between global temperature and ENSO, Geophys. Res. Lett., 32, L09701, doi:10.1029/2005GL022875/2005, 2005.

Vautard, R. and Ghil, M.: Singular spectrum analysis in nonlinear dynamics, with applications to paleoclimatic time series, Physica D, 35, 395-424, 1989.

Weng, H. and Lau, K.-M.: Wavelets, period doubling, and timefrequency localization with application to organizationmof convection over the tropical western Pacific, J. Atmos. Sci., 51, 2523-2541, 1994.
Wiles, G. C., D'Arrigo, R. D., and Jacoby, G. C.: Gulf of Alaska atmosphere-ocean variability over recent centuries inferred from coastal tree-ring records, Climatic Change, 38, 289306, doi:10.1023/A:1005396027562, 1998.

Yadav, R. R., Park, W. K., and Bhattacharyya, A.: Springtemperature variations in western Himalaya, India, as reconstructed from tree-rings: AD 1390-1987, Holocene, 9, 85-90, 1999.

Yadav, R. R., Park, W. K., Singh, J., and Dubey, B.: Do the western Himalayas defy global warming?, Geophys. Res. Lett., 31, L17201, doi:10.1029/2004GL020201, 2004.

Yasunari, T.: Zonally propagating modes of the global east-west circulation associated with the Southern Oscillation, J. Meteorol. Soc. Jpn., 63, 1013-1029, 1985. 